\title{
Study on Perception of Enterprise Human Resource Crisis and Its Prevention
}

\author{
Yan Wan ${ }^{1}$ \\ ${ }^{1}$ Nanchang Institute of Science \& Technology, Nanchang, Jiangxi, 330108
}

59624917@163.com

Keywords: Enterprise; Human Resource Crisis; Crisis Prevention

\begin{abstract}
The rise and fall to reflect the rise and fall of the level of corporate governance, and corporate human resources are restricting the level of management. With the growing competition in the market and our continued expansion of business scale, the human resources crisis people get more and more attention. From the perspective of the crisis management process, combined with the theory of human resource management, in line with the idea of focusing on preventive measures beforehand and a matter of managing human resources crisis management and human resources on the perception of the crisis and prevent a study. The field study for the existing deficiencies, this paper defines the human resource crisis, the use of technology and scientific management methods, through the human resources crisis get outside to the inside analysis and synthesis of human resources and human crisis triggered mechanism resource crisis perceptual model, and validated by empirical research perceptual model.
\end{abstract}

\section{Introduction}

As we all know, human resources are one of the most important resources, enterprise almost all the work is done by people, the quality of work, efficiency depends on the level of quality of employees, enterprises can adapt to environmental changes, in fierce competition in the market can be in a favorable position, the key is whether a company has high-quality staff. To become a first-class enterprise, the key is to have a first-class talent. Therefore, the business community is often a saying: investment rather has a first-class talent, and the company has only second-rate technology, investments have to be better than a first-class technology, and the company has only a second-rate talent. The company's most important task is to improve human resource management, establish beneficial to attract and retain qualified personnel, personnel incentive mechanism and atmosphere, to prevent brain drain, human resources and thus avoid a crisis due to mismanagement caused.

In today's complex market environment, as market competition intensifies and the advent of the knowledge economy enterprises are facing the external environment and internal factors, etc. caused by the crises, and more and more types of crisis, to produce a serious impact on business performance. Complex crisis, companies have lost enough to make an accurate judgment; severe crisis, enough to allow enterprises are facing life and death situation. In enterprises are facing a variety of crises or potential, human resources crisis is more subtle, and it is often easy to overlook the enterprise. Corporate crisis management status 0 research by the polling company, the crisis management group Tsinghua University and China Hewlett-Packard Co. to work together to complete the show, China has nearly 60 percent of state-owned enterprises have the human resources crisis, while about 25\% The state-owned enterprise that human resources crisis had a serious impact on its business, about $30 \%$ of state-owned enterprises have experienced or are experiencing a crisis in human resources caused by the high rate of employee turnover, and have experienced or are experiencing unexpected senior management personnel Turnover caused by the crisis up to $41 \%$ the proportion of state-owned enterprises, have the same experience of foreign and private sector rates were only about $25 \%$ and $33 \%$. Thus, the loss of senior management personnel is an important manifestation of human resource crisis. In addition, human resource crisis also include the sudden resignation of the main backbone of the enterprise, obvious flaws payroll system, 
the loss of key employees, even employees on strike this personnel crisis more extreme and serious phenomenon. Chinese enterprises sorely lacking is neither money nor technology, but not the market, but people, especially the outstanding senior management personnel.

\section{The Reason of Human Resource Crisis}

Business success reflects the rise and fall of the enterprise management level, and the company's human resources are restricting the level of management. With the growing competition in China's market, expanding the scale of enterprises, human resources crisis has drawn increasing attention. Combined with practical experience and combing previous studies, the present study suggests that the human resources crisis facing Chinese enterprises summed up the main manifestations are the following:

With economic globalization, dramatic changes in the external environment, an organization that only the times, constantly learning, in order to continuously improve competitiveness; on the contrary, if shortsighted organization, to meet the temporary results do not make progress in the face of brutal competition, a move accidentally, it will fall into crisis, leading loser. Especially in the era of knowledge and networking organization not only to learn, improve learning ability, but also the level of learning should be more widely used. Such as customer relationship management (CRM), enterprise resource planning (ERP), supply chain management (SCM), electronic commerce (e-Business), etc., are encompassed within the scope of the study.

Therefore, enterprises should be established as a learning organization, enabling organizations to form organizational learning organization, and become one of the basic principles of their own, through this form of organization understand the environment, adapt to the environment, and then act on the dynamic environment, through individual learning and organizational learning combine to enhance the organization's overall learning ability and competitiveness of enterprises, so as to meet the increasingly intense competition.

According to economic theory, the psychological contract theory and practice of human resource management crisis attribution analysis, human resources management and organizational behavior will be rational actors, organizational system, cultural factors, and the influence of external market environment relationship. So, I think that from two aspects to analyze the impact of various factors on the human resource crisis.

First, the role of environmental crisis is in human resources point of view. Under normal circumstances, changes in employee status by enterprises other than the concept of individual factors environment, macro environment and affect the external environment. Enterprises in the process of achieving its strategic development goals, when the business development strategy, corporate culture, organizational structure and management style in any one change, will affect the attitude of its staff in their organizations, and this time, staff will their value orientation and value expectations adjust his attitude toward business according to adapt to the environment. When employees can not adapt to the organization's environment, he will appear rebellious attitude. In this case, employees want managers to be able to find his attitude change, and by adjusting the external environment to stabilize its attitude toward the enterprise, if not timely adjustment of the organizational environment, it will lead to dissatisfaction with the work of employees, working in negative slack, even choose to leave. At this time, the overall state of the staff began to deteriorate. If you generalize from this perspective, then, the crisis behavior of human resources is not satisfied because of the organization's environment, suited triggered.

Secondly, we should consider from the effects of the crisis triggered by managers' view. As mentioned above organizational environment greatly affect the staff's attitude, however, the environment is just a medium, truly decisive impact on employee attitudes and methods is management organizations. Human resources crisis subjectivity characteristic tells us, managers, policy-makers is caused by changes in the organizational environment doer, they are not satisfied with the attitude of the staff to improve and ease the organization's environment plays a key role. Therefore, staff attitude towards organization's environment and its essence can be equal to its attitude to the organization and management models and approaches. After all, management 
practices and organizational environment affects both the individual employee; moreover, individual views of the staff of the organization are the opinion of environmental managers. From this point of induction, then the behavior of the human resources crisis is the result of imperfect management system, unreasonable management models and methods, as well as discord organization's environment interaction.

Based on the above analysis, the author tries to build mechanistic models of human resource crisis, an organization intended to set forth, is what factors Organization's human resources crisis a key influence, but also to find the human resources management system, and its relationship with human black box resource crisis in the relationship, what is the role of mediating variables in play conduction.. Interviewees mainly from Jinan enterprises, mainly related to state-owned enterprises (Shandong Expressway Group and affiliated enterprises, Shandong Jinan Iron and Steel Group, Jinan refineries), the private sector (Shandong, China Resources Group), joint-stock company (Shandong Sanlian Group and its subsidiaries. ) and other nine companies. Each company selected five employees, whose jobs involve engineers, operators, line managers, a total of 45 people. Interview process consists of himself and assistants completed interviews about thirty minutes each time, the theme of entering the business around, the conditions provided for employees of the staff, the signing of the agreement corporate commitment to employees, as well as business-to-employees managed. After the interview, the investigator himself organizational environment and management model interviewee mentioned contents are classified, summarized and finishing. Finally, I think we can start from the following point of view to analyze the process of human resources caused by the crisis.

\section{The Countermeasures for Human Resource Crisis}

Prevent human resource crisis is a source of human resource management activities throughout the entire process, this activity from a selection of business people, through staff recruitment and staff retention and a series of links. Empirical Analysis of the foregoing, we have got a significant impact on the human resources crisis in four dimensions: external recruitment, staff training, performance evaluation and incentive system. Therefore, based on these four dimensions we have put forward the human resources crisis prevention strategy that will help to control the human resource crisis triggered at the source.

That the system point of view, corporate human resource management can be seen as an input to management practices, the output is the result of system management, the role of the environment and the system can be divided into the external environment and internal environment categories. The fourth chapter studies the use of the organizational environment in harmony as the distinction between high and low levels of organization of the main indicators of internal environment to test its interference effect on human resource management practices and human resource crisis signs. Specific indicators with harmonious corporate culture, rational organizational structure, improve the institutional system, strategic prospective, the principle of fairness, management processes and innovative interactive coordination, etc. to describe. In the data analysis process, with interaction variables organizational environment and human resource management practices of each dimension as a new variable stepwise regression analysis showed that the training system, based on the results of the performance evaluation, incentive pay system, employee participation and employee job security This relationship between the five human resource management practices and human resource crisis signs are subject to interference and regulation organization's environment.

Red-class enterprise human resource crisis is a dangerous stage) staff morale, slacking, enthusiasm decreased, resulting in lower production efficiency in the organization interpersonal conflict significantly; has shown indicators of crisis, may result in direct economic losses and affect to normal operation and long-term development of the organization, should take precautions immediately.

Talent burnout stage the most prominent symptom is loss of passion for work, go to work and just; negatives others, bad attitude, not the pursuit of progress and so on. When complained stage no opportunity to vent grievances, people may be to maintain psychological balance through this way. 
Although not intend to leave this time talent, but depression, bad mood, easy to get angry, or depressed and autistic. This stage can be carried out staff burnout management.

\section{Conclusion}

On the basis of the mechanism of human resources caused by the crisis, this study shows the perception model of the human resource crisis, through empirical research, demonstrates the intrinsic link human resource management practices of the entire process and the crisis signs and manifestations, the introduction of organizational environment as an adjustment variable. By means of statistical analysis tools for data analysis research scale, and get the following eight human resource crisis factors: human resource planning, training systems, internal career development, incentive compensation systems, employee participation, employee job security, based on the results performance evaluation and external recruitment.

\section{References}

[1] Zhao Hongli. Employees Complain Butterfly Effect. Managers, 2005 (8): 74-75.

[2] He Zhengchu. Crisis Management: Organization and Organizational Management Perspective. Central South University .2004.

[3] Cheng Hao. Crisis Management of Chinese Telecom Companies. Wuhan University, 2005.

[4] Si Donglin. Enterprise Human Resources Crisis Management Research. University of Science and Technology of China, 2005. 